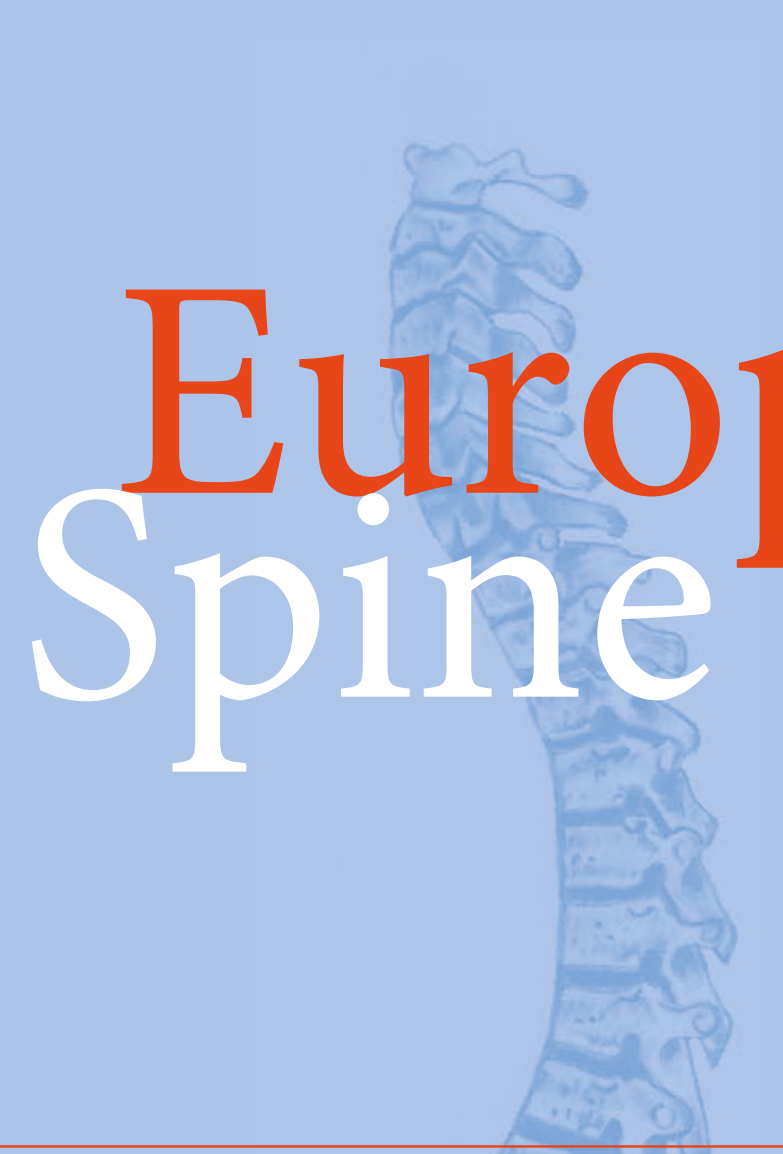

Case Reports

Accepted between

04 May 2012 and

04 May 2013

\section{Publication of Case Reports}

Case Reports will be published electronically only in a yearly online supplement to the journal.

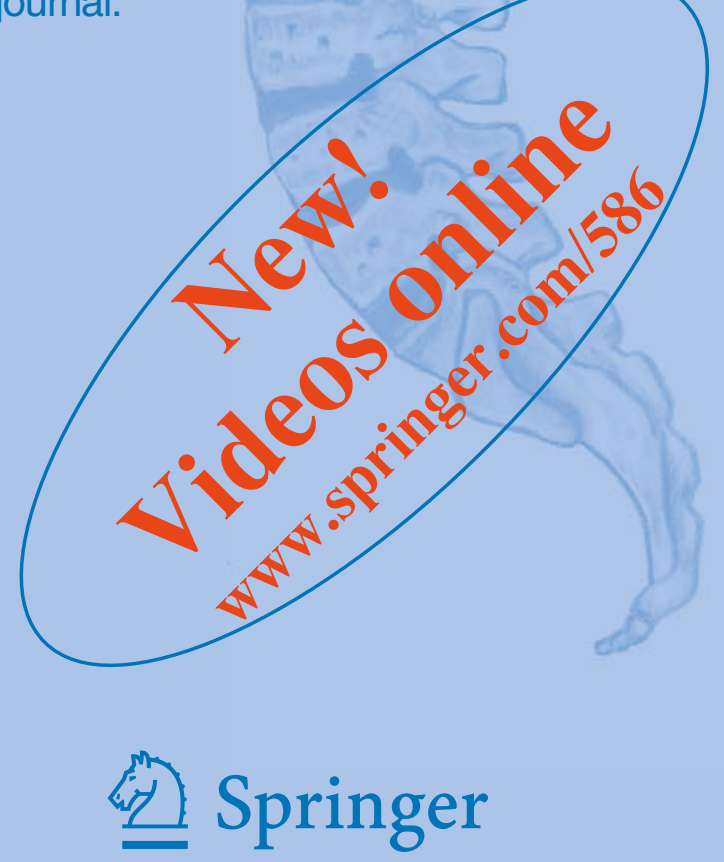

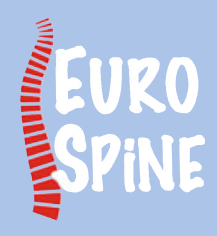

Affiliated societies

Austrian Spine Society

Brazilian Spine Society

Cervical Spine Research Society (European Section)

Czech Spine Surgery Society

Deutsche Wirbelsäulengesellschaft

Dutch Spine Society

EuroSpine Society

French Society of Spine Surgery

GEER (Grupo de Estudio de Enfermedades del Raquis)

G.I.S. (Italian Spine Society)

Hellenic Spine Society

Polish Society of Spinal Surgery

SILACO (Sociedad IberoLatinoamericana de Columna)

South African Spine Society

Turkish Spine Society

Open Operating Theatre

Videos available online at:

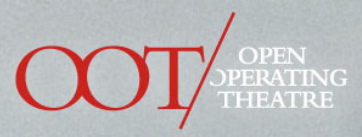

www.springer.com/586

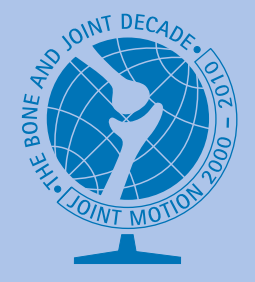

Indexed in PubMed/Medline and

Science Citation Index Expanded/Journal Citation Report 22 (Suppl 3) S297-S525 May 2013 
Contents

DOI 10.1007/s00586-013-2782-9

S297-S301

Chinese Sections

\section{Case Reports}

Isolated atypical spinal tuberculosis mistaken for neoplasia: case report and literature review Y. Yu, X. Wang, B. Du, W. Yuan, B. Ni, D. Chen DOI 10.1007/s00586-012-2294-Z

S302-S305

Unusual association of intraspinal extramedullary teratoma with congenital scoliosis in an elderly adult: case report and literature review

H. Jiang, Z. Xiao, X. Zhan, Q. Chen, M. He, L. Lu DOI 10.1007/s00586-012-2385-x

S306-S310

A tail of sacral agenesis: delayed presentation of meningocele in sacral agenesis C. C. Gillis, A. A. Bader, M. Boyd DOI $10.1007 / \mathrm{s} 00586-012-2347-3$

S311-S316

Thoracolumbar intramedullary subependymoma with multiple cystic formation: a case report and review

M. Iwasaki, K. Hida, T. Aoyama, K. Houkin

DOI 10.1007/s00586-012-2357-1

S317-S320

Asymptomatic thoracic Pantopaque cyst mimicking an intradural extramedullary lipoma on MR images

S.-K. Lee, D. H. Kim, S.-H. Kim, D.-J. Lim

DOI 10.1007/s00586-012-2364-2

S321-S328

Intradural extramedullary primary hydatid cyst of the spine: a case report and review of literature

I. Lotfinia, S. Sayyahmelli, A. Mahdkhah, M. M. Shoja

DOI 10.1007/s00586-012-2373-1

S329-S336

Spontaneous chronic epidural hematoma of the lumbar spine mimicking an extradural spine tumour

S. Fuster, S. Castañeda, E. Ferrer, J. Wang, J. Poblete

DOI 10.1007/s00586-012-2402-0

S337-S340

Instability of treated vertebrae after balloon kyphoplasty causing paraparesis in osteoporotic vertebral compression fracture: a report of two cases

T. Ohba, S. Ebata, D. Clinton, K. Koyama, H. Haro

DOI 10.1007/s00586-012-2414-9

S341-S345

Spinal subdural hematoma as a complication of spinal surgery: can it happen without dural tear? H. Gakhar, R. Bommireddy, Z. Klezl, D. Calthorpe

DOI $10.1007 / \mathrm{s} 00586-012-2427-4$

S346-S349

Iliac artery perforation and treatment during lumbar disc surgery by simple balloon tamponade A. Olcay, K. Keskin, F. Eren

DOI 10.1007/s00586-012-2436-3

S350-S352

Pure hyperextension injury of the lower lumbar spine with an ureteral impingement

I.-S. Oh, D.-G. Chang, Y.-H. Kim, K.-Y. Ha

DOI 10.1007/s00586-012-2450-5

S353-S356

Endoscopic excision of C2 Osteoid Osteoma: a technical case report

L. Amendola, M. Cappuccio, L. Boriani, A. Gasbarrini

DOI 10.1007/s00586-012-2467-9

S357-S362

Two-stage multilevel en bloc spondylectomy with resection and replacement of the aorta T. Gösling, M. A. Pichlmaier, F. Länger, C. Krettek, T. Hüfner

DOI 10.1007/s00586-012-2471-0

S363-S368 
Cervical spinal epidural abscess after oesophagoscopy

D. Radulovic, L. Vujotic

DOI 10.1007/s00586-012-2478-6

S369-S372

Ewing sarcoma of the thoracic epidural space in a young child

S. Kobayashi, J. Takahashi, K. Sakashita, M. Fukushima, H. Kato

DOI 10.1007/s00586-012-2481-y

S373-S379

Surgical treatment of Klippel-Feil syndrome with basilar invagination

N. Ogihara, J. Takahashi, H. Hirabayashi, K. Mukaiyama, H.Kato

DOI $10.1007 / \mathrm{s} 00586-012-2489-3$

S380-S387

Juxtafacet cyst infection

S. M. Jones-Quaidoo, K. McCarthy, J. Dimar

DOI 10.1007/s00586-012-2503-9

S388-S393

An uncommon case of Mycoplasma hominis infection after total disc replacement

C.-H. Flouzat-Lachaniette, J. Guidon, J. Allain, A. Poignard

DOI 10.1007/s00586-012-2511-9

S394-S398

Posterior spinal cord herniation: a novel occurrence following surgery for an intramedullary

cyst at the thoracolumbar junction

R. Zakaria, J. R. Ellenbogen, I. S. Grewal, N. Buxton

DOI $10.1007 / \mathrm{s} 00586-012-2515-5$

S399-S403

Intradural lumbar disc herniation: report of five cases with literature review

L. G. Ducati, M. V. Silva, M. M. Brandao, F. R. Romero, M. A. Zanini

DOI $10.1007 / \mathrm{s} 00586-012-2516-4$

S404-S408

Dysmorphic facies and diffuse posterior spine ankylosis in a patient with unusual form of spondyloenchondrodysplasia (Spranger type IV)

A. A. Kaissi, F. B. Chehida, M. B. Ghachem, K. Klaushofer, F. Grill

DOI $10.1007 / \mathrm{s} 00586-012-2518-2$

S409-S415

Multiple-level ossification of the ligamentum flavum in the cervical spine combined with calcification of the cervical ligamentum flavum and posterior atlanto-axial membrane H. Inoue, A. Seichi, A. Kimura, T. Endo, Y. Hoshino

DOI 10.1007/s00586-012-2521-7

S416-S420

Isolated abducens nerve palsy due to cerebrospinal fluid leakage following lumbar discectomy: a rare clinical entity

J. Joo, S. H. Yoon, K.-J. Kim, T.-A. Jahng, H.-J. Kim

DOI $10.1007 / \mathrm{s} 00586-012-2545-\mathrm{z}$

Congenital costo-vertebral fibrous band and congenital kyphoscoliosis: a previously unreported combination

T. Eid, B. Ghostine, G. Kreichaty, P. Daher, I. Ghanem

DOI 10.1007/s00586-012-2570-y

Unilateral atlantal lateral mass hypertrophy associated with atlanto-occipital fusion

E. Onishi, A. Sakamoto, S. Murata, S. Nakamura, M. Matsushita

DOI $10.1007 / \mathrm{s} 00586-012-2574-7$

S429-S433

Acute calcific tendinitis of the longus colli muscle: case report and review of the literature

A. H. Zibis, D. Giannis, K. N. Malizos, P. Kitsioulis, D. L. Arvanitis

DOI 10.1007/s00586-012-2584-5

S434-S438

Surgical treatment for unilateral cervical facet dislocation in a young child aged

22 months old: a case report and review of the literature

Y. Chen, X. Wang, D. Chen, X. Liu

DOI 10.1007/s00586-012-2590-7

S439-S442 
Erratum

\section{Case Reports}


Surgical treatment in a patient with Klippel-Feil syndrome and anterior cervical meningomyelocele: a case report and review of literature

B. Brokinkel, K. Wiebe, V. Hesselmann, T. J. Filler, C. Ewelt, C. Müller-Hofstede,

W. Stummer, M. Klingenhöfer

DOI 10.1007/s00586-013-2769-6

S517-S520

Bifocal extra- and intradural melanocytoma of the spine: case report and literature review

N. A. Foit, M. C. Neidert, C. M. Woernle, E. J. Rushing, N. Krayenbühl

DOI $10.1007 / \mathrm{s} 00586-013-2773-\mathrm{x}$

S521-S525

This supplement was not sponsored by outside commercial interests. It was funded entirely by the publisher.

Further articles can be found at springerlink.com

Instructions for authors

for Eur Spine $J$ are available at www.springer.com/586 